\title{
Development of a molecular marker based on chloroplast gene for specific identification of Korean Hibiscus (Hibiscus syriacus 'Simbaek')
}

Rongbo Wang ${ }^{1}$, Sang Yong Park², Sul Woong Park², Aditi Mitra Puja ${ }^{1}$ and Yeon-Ju Kim*

\begin{abstract}
Due to the rise in substitution and adulteration of herbal products, as well as the lack of genetic information on Hibiscus plants, more molecular markers are needed to understand the genetic diversity and avoid their misidentification. There are many allelic variants of the functional genes in Hibiscus and other plants, which control their respective phenotypes and other characteristics. Identifying alleles of the desired trait by determining diversification through gene-typing allele-specific markers for authentication is, therefore, a potent strategy. The purpose of this study was to use insertion/deletion (InDel) markers to identify Hibiscus syriacus cultivars. We developed a novel InDel marker for Korean Hibiscus 'Simbaek', based on the trnL-F region of the chloroplast gene. Through this InDel site, a modified specific primer pair and a novel multiplex polymerase chain reaction (PCR) system were developed for specific identification of the Korean Hibiscus Simbaek cultivar. The molecular markers developed in this study were highly specific and accurately authenticated as Simbaek from the five main cultivars of $H$. syriacus. Taken together, the described method is a potential tool for the identification and selection of germplasm resource of Simbaek cultivar.
\end{abstract}

Keywords: Hibiscus syriacus, InDel, Multiplex PCR, Simbaek, trnL-F

\footnotetext{
*Correspondence: yeonjukim@khu.ac.kr

${ }^{1}$ Graduate School of Biotechnology, and College of Life Science, Kyung

Hee University, Yongin, Gyeonggi-do 17104, Republic of Korea

Full list of author information is available at the end of the article
} original author(s) and the source, provide a link to the Creative Commons licence, and indicate if changes were made. The images or other third party material in this article are included in the article's Creative Commons licence, unless indicated otherwise in a credit line to the material. If material is not included in the article's Creative Commons licence and your intended use is not permitted by statutory regulation or exceeds the permitted use, you will need to obtain permission directly from the copyright holder. To view a copy of this licence, visit http://creativecommons.org/licenses/by/4.0/. 


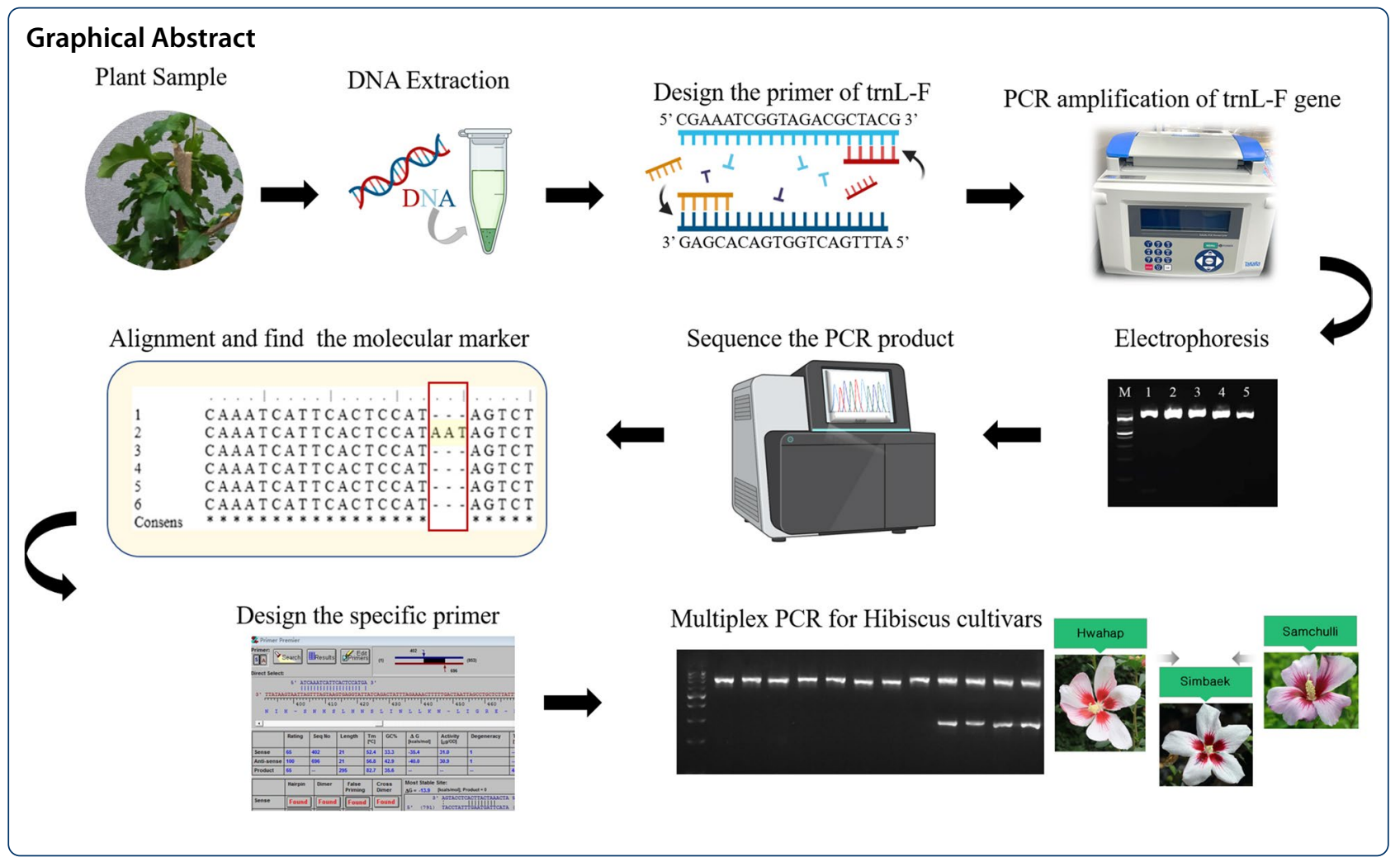

\section{Introduction}

Hibiscus syriacus is a deciduous shrub belonging to the genus Malvaceae. Hibiscus syriacus originated in the Korean Peninsula and southern China, and later spread to the Indian subcontinent and middle-eastern regions. In temperate regions, $H$. syriacus is a common ornamental species with white, pink, red, or purple flowers [1]. In addition to its ornamental value, dried flowers and root bark of $H$. syriacus are known for their anticancer [2], antidepressant [3], and antioxidant [4] properties. Hibiscus syriacus is also mentioned in the Korean national anthem as the national flower. Since there is substantial history and culture associated with the flower, new varieties have been actively developed in Korea by natural and systematic selection. Each Korean hibiscus variety has unique and improved agronomic traits, such as appearance, water resistance, and disease resistance traits. The Korean hibiscus cultivar, Simbaek, was developed from two basic cultivar lines (Hwahap and Samchunli) and registered in 2014. Simbaek is used as a street-side landscaping plant because of the beautiful flowers and lush branches. It has also been found to have better anticancer effects than the other cultivars (Additional file 1: Fig. S1). In herbal markets, American Hibiscus (Hibiscus sabdariffa) is often regarded as an adulterant of Korean Hibiscus which also brings a lot of trouble to consumers.Traditionally, confirming the authenticity of species or cultivars relies on morphological characteristics, such as growth environment, floral morphology, and other characteristics of the plant [5]. However, as majority of the herbal products are packaged in the form of powders that do not bear the original features of the plants, identification of the latter by morphological and histological techniques becomes difficult.

DNA molecular markers have several advantages over morphological characterization and chemical profiling for identifying the origin of different varieties, since the genetic composition is unique for each variety irrespective of its physical form and less affected by environmental factors as well as developmental stages [6-8]. The insertion/deletion markers (InDels), which are structural variations caused by polymerase slippage, transposons, and unequal exchange, usually include insertion/deletion and extension of base pairs. They are distributed in large numbers throughout the genome and are closely related to the gain/loss of biological functions [9-11]. InDels have been successfully used in rice [12], Arabidopsis thaliana [13], and Panax ginseng [14] germplasm genetics, in which genetic and association maps of different plants are constructed. In addition, genotyping using InDels through conventional gel electrophoresis does not produce non-specific bands. In some previous studies, InDels were found to be more polymorphic than microsatellite markers [15]. 
Table 1 Information of the plant samples used in the study

\begin{tabular}{llll}
\hline Hibiscus samples & $\begin{array}{l}\text { Registration } \\
\text { number }\end{array}$ & Origin & $\begin{array}{l}\text { GenBank } \\
\text { accession number } \\
\text { of trnL-F region }\end{array}$ \\
\hline Samchunli & 1481 & Korea, Cheonan & MZ127173 \\
Simbaek & 5259 & Korea, Cheonan & MZ127174 \\
Jinsun & 6335 & Korea, Cheonan & MZ127175 \\
Jamyung & 5778 & Korea, Cheonan & MZ127176 \\
H. sabdariffa & - & USA & JQ625356.1 \\
\hline
\end{tabular}

Table 2 Primer sequences used in this study

\begin{tabular}{lll}
\hline Primer name & Direction & Nucleotide sequence $\left(\mathbf{5}^{\prime} \mathbf{-} \mathbf{3}^{\prime}\right)$ \\
\hline $\operatorname{trnL}$ & Forward & CGAAATCGGTAGACGCTACG \\
$\operatorname{trnF}$ & Reverse & ATTTGAACTGGTGACACGAG \\
$\mathrm{SimF}$ & Forward & ATCAAATCATTCACTCCATGA \\
$\mathrm{SimF}$ & Reverse & AGGATACGCTTGTAAAATGGC \\
\hline
\end{tabular}

Nevertheless, to the best of our knowledge, InDel markers have rarely been applied to the molecular genetics of $H$. syriacus. In this study, we report the first InDel marker of Simbaek cultivar developed using an easy and reproducible multiplex PCR method that amplifies the trnL-F region. This approach can be used for basic and applied research on $H$. syriacus, which as mentioned above, has potentially immense value.

\section{Materials and methods}

\section{Plant and materials}

This study was carried out in accordance with the guidelines provided by Kyung Hee University, Yongin-si, Gyeonggi-do, Republic of Korea. Four Korean cultivars of $H$. syriacus and $H$. sabdariffa were provided by Jangho Farm in Nonsan, Chungcheongnam-do, and the plant species were assessed by Dr. Kyung-gu Shim who has developed more than 100 new cultivars in Korea. All voucher specimens were morphologically identified and voucher specimen numbers are shown in Table 1.

\section{DNA extraction and PCR amplification of trnL-F genome}

Leaves of the five different Hibiscus cultivars were placed in liquid nitrogen for $1 \mathrm{~min}$ and crushed into powder. Genomic DNA was isolated using the Exgene ${ }^{\mathrm{TM}}$ Plant SV mini kit (GeneAll Biotechnology Co., Seoul, Korea), according to the manufacturer's instructions. The primer pairs used for the amplification of trnL-F region were synthesized by Macrogen (Seoul, Korea); the sequences of the universal primers are listed in Table 2 [16]. The PCR reaction mixture consisted of $50 \mathrm{ng}$ of DNA, $0.5 \mu \mathrm{M}$ of primers, $10 \mu \mathrm{L}$ of Taq polymerase (GeneAll
Biotechnology Co., Seoul, Korea), and $5 \mu \mathrm{L}$ of distilled water. PCR products were analyzed by electrophoretic separation in a submarine horizontal agarose slab gel apparatus. For running the DNA samples, a gel strength of $2 \%$ agarose was dissolved in $0.5 \mathrm{X}$ TAE buffer followed by heating in microwave oven. After cooling to approximately $55{ }^{\circ} \mathrm{C}, 0.05 \mu \mathrm{L} / \mathrm{mL}$ GelGreen ${ }^{\circledR}$ Nucleic Acid Gel Stain (Fremont, CA, USA) was added. Then, $300 \mathrm{~mL}$ of $0.5 \mathrm{X}$ TAE buffer was poured to sufficiently submerge the gel in the electrophoresis tank. Electrophoresis was performed at a constant voltage of $5 \mathrm{~V} / \mathrm{cm}$ until the bromophenol dye reached almost the end of the gel. A UV-trans illuminator was used to visualize the DNA fragments of different sizes separated in the gel (Fig. 1).

\section{Sequencing and analysis of the PCR products}

The PCR products were purified using a total fragment DNA purification kit (iNtRON Biotechnology, Seongnam, Korea), following the manufacturer's instructions. The purified products were sequenced by Genotech Co. (Daejeon, Korea) using the designated primers. The base sequence was decoded by cycle sequencing, using the BigDye Terminator Kit (Thermo Fisher Scientific, WA, MA, USA). On completion of the PCR, the purified product was dissolved in sterile water or HDF (Hi-Di Formamide) and mounted on the device (ABI 3730xl DNA analyzer) for electrophoresis using capillary method. The sequences of the trnL-F region were compiled using SeqMan software (SeqMan 2, DNASTAR, Inc., WI, USA), and BioEdit program (BioEdit 7.2.5, Ibis Biosciences, CA, USA) was applied [8]. ClustalW2 (http://www.ebi.ac.uk/ Tools/clustalw2/) was used to perform multiple sequence alignments.

\section{Design and modification of specific primers}

Specific primers, SimF and SimR, were designed according to the InDel site of Simbaek (Figs. 2, 3). A mismatch of the primer was incorporated into SimF by substituting $\mathrm{A}$ for $\mathrm{G}$ at the second base from the $3^{\prime}$ end. Then, the corresponding reverse primer, SimR, was designed. The sequences and positions of the specific primers are listed in Table 1 and Fig. 3, respectively.

\section{Multiplex-specific PCR}

Since the InDel site was found in the trnL-F sequences of the chloroplast gene of $H$. syriacus, the primer pair trnF and trnL was used as the universal primer set for the identification of all Hibiscus cultivars. SimF and SimR were designed and multiplex PCR was performed for the specific authentication of Simbeak from other H. syriacus cultivars and $H$. sabdariffa.

PCR was performed using $50 \mathrm{ng}$ of DNA in a reaction volume of $20 \mu \mathrm{L}$ that included $10 \mu \mathrm{L}$ of Taq DNA 


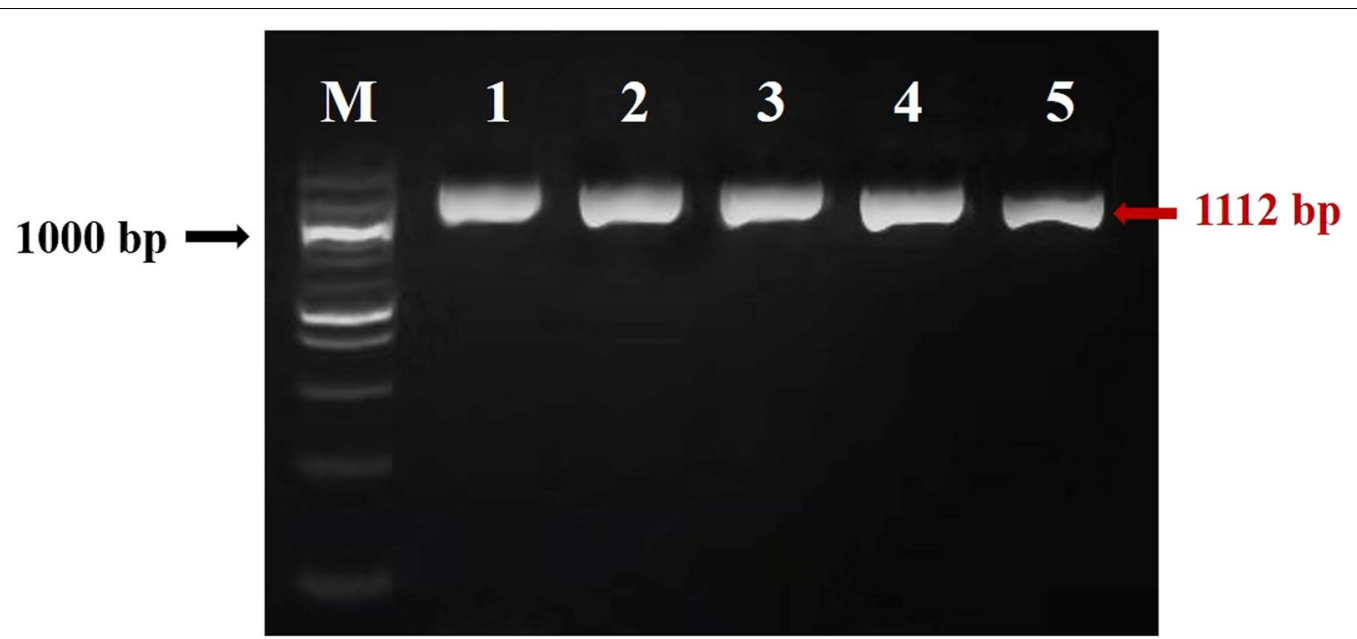

Fig. 1 PCR products of five Hibiscus cultivars. Lane M: 100 kb DNA ladder; lane 1: samples of 'Samchunli' (H. syriacus); lane 2: samples of 'Simbaek' (H. syriacus); lane 3: samples of 'Jinsun'; lane 4: samples of 'Jamyung' (H. syriacus); lane 5: samples of $H$. sabdariffa

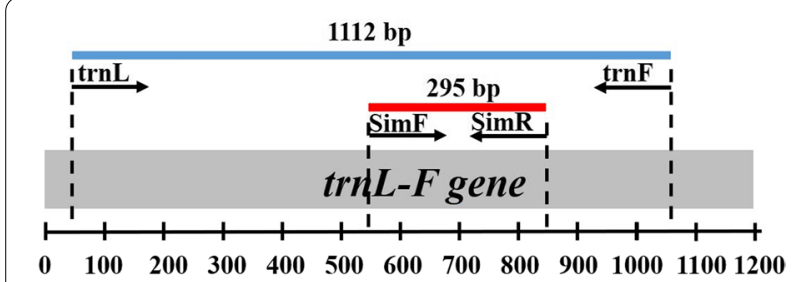

Fig. 2 Schematic diagrams of the PCR-amplified trnL-F region of Hibiscus. The PCR product amplified with universal primer sets, 'trnL' and 'trnF' and the PCR product amplified with Simbaek-specific primer, 'SimF' and 'SimR'

polymerase (GeneAll Biotechnology Co., Seoul, Korea) and $0.5 \mu \mathrm{M}$ of each primer (trnF, trnL, SimF, and SimR). The cycling conditions were as follows: $5 \mathrm{~min}$ at $94{ }^{\circ} \mathrm{C}$, followed by 33 cycles of $30 \mathrm{~s}$ at $94{ }^{\circ} \mathrm{C}, 30 \mathrm{~s}$ at $56{ }^{\circ} \mathrm{C}, 40 \mathrm{~s}$ at $72{ }^{\circ} \mathrm{C}$, and a final extension of $7 \mathrm{~min}$ at $72^{\circ} \mathrm{C}$.

\section{Results and discussion}

\section{Sequencing analysis of the PCR products}

Since chloroplast genome sequences in plants evolve slowly and are highly conserved between species within a genus, they can be utilized for species identification and genetic diversity studies [17]. A trnL (UAA) intron and an intergenic spacer trnL (UAA)-trnF (GAA) are present in the trnL-F region of chloroplast DNA. Owing to its easy amplification, trnL-F has been proven to be a useful gene for the identification of many plants using primers homologous to its exons [17-19]. The trnL-F regions of the five cultivars, including 20 samples, were

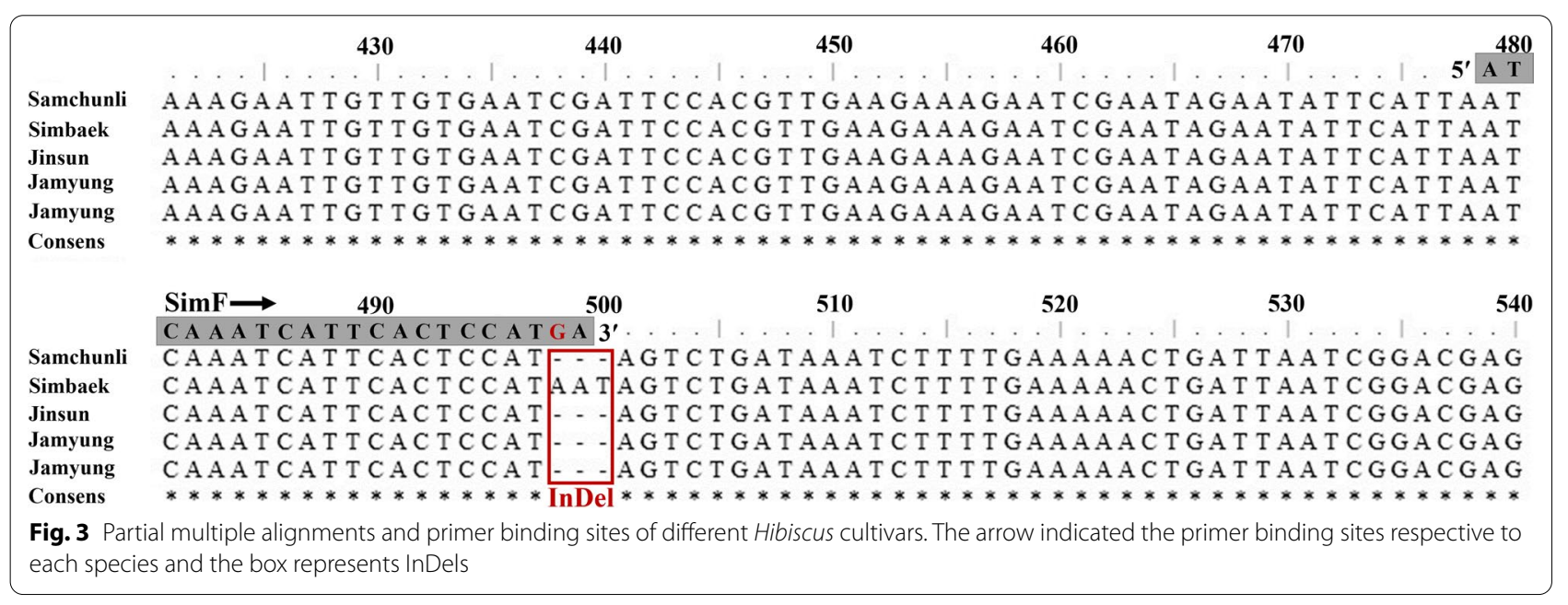


amplified and sequenced. The universal primer set for the trnL-F region produced amplified PCR products of approximately $1100 \mathrm{bp}$ lengths (Fig. 1). The four trnL-F sequences have been deposited at NCBI with the accession numbers MZ127173 (Samchunli), MZ127174 (Simbaek), MZ127175 (Jinsun), and MZ127176 (Jamyung).

\section{Using the InDel marker for Hibiscus cultivar identification}

Although considerable development has been achieved in recent years, problems such as genetic pollution and variety degradation, in Hibiscus cultivation still persist, which have seriously affected the breeding and functionrelated studies of the plant. The accurate identification of different high-quality cultivars of $H$. syriacus is crucial for the cultivation of Hibiscus medicinal plants. DNAbased molecular markers, such as random amplified polymorphic DNA (RAPD) [5] and restriction fragment length polymorphism (RFLP) [20], have been used for the identification of plant and animal species. Although the complete chloroplast genome sequence of $H$. syriacus has been published [21], there are only a few reports on Hibiscus species-specific markers. Due to intra-species polymorphism between different cultivars of Hibiscus, developing the exact method to identify Hibiscus is essential for breeding and utilizing the plant resources. Recently, InDel, a new type of molecular marker regarded as an emerging technology for genomic identification, has been broadly applied in ecological studies [22]. InDel markers have characteristics, such as genetic inheritance and codominance, but to the best of our knowledge, there are no InDel markers developed for Hibiscus. Thus, to establish an economic and efficient method for the authentication of different $H$. syriacus cultivars, InDel genotyping using multiplex-specific PCR was performed. In view of the Simbaek cultivar-specific InDel sites explored in the trnL-F region, a pair of specific primers, SimF (5'-ATCAAATCATTCACTCCATGA- $\left.3^{\prime}\right)$ and
SimR (5'-AGGATACGCTTGTAAAATGGC-3'), were designed with specific mismatches (Fig. 2). As shown in Fig. 3, the substitution of $\mathrm{G}$ for $\mathrm{A}$ at the third base from the $3^{\prime}$ terminus was deliberately introduced to ensure its absolute specificity and reliable discrimination between the alleles.

\section{Authentication of Simbaek cultivar using multiplex-specific PCR}

Specific primers, together with the universal primers of the trnL-F region, were used to differentiate the cultivars Samchunli, Simbaek, Jinseon, Jamyung, and H. sabdariffa, in multiple allele-specific PCR. As shown in Fig. 4, the DNA of different hibiscus cultivars cross-annealed with the specific and universal primers amplified into two fragment patterns. To determine the exact sequence and size of the multiplex PCR products, the amplicons were cloned and sequenced. A band at 295 bp was observed for Simbaek, indicating an insertion allele in the the trnLF region from Simbaek, while only one band at 1112 bp was observed for the other cultivars. Two regions of the trnL-F gene from chloroplasts of different $H$. syriacus cultivars were amplified using specific and universal primers. Mismatches in the specific primers increased specificity of the PCR method and avoided non-specific amplification. Moreover, no cross-amplification or interference was observed. Taken together, the developed PCR assay ensured reliable authentication of Simbaek cultivar via simultaneous amplification of allele in a single reaction.

To ensure accuracy of results, the molecular identification system usually contains three conditions: primer versatility, sequence quality, and species distinction. However, for molecular marker research, the universality of primers is the most important prerequisite, because the region/site they bind to is unknown $[23$, 24]. This factor was also important in our research.

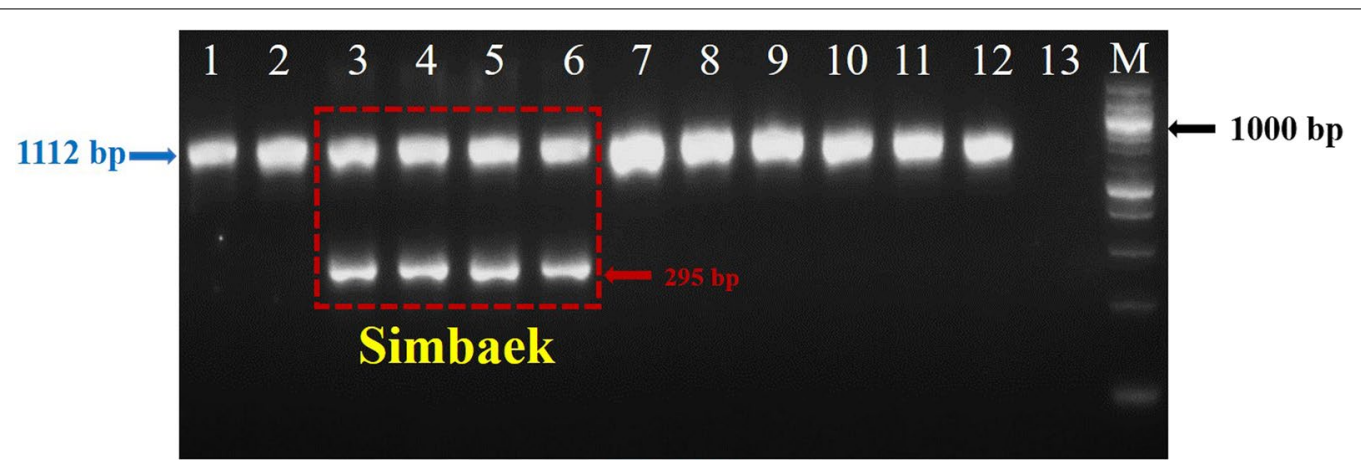

Fig. 4 The PCR products in multiplex PCR using the primers, 'trnL', 'trnF', 'SimF', and 'SimR'. Lane M: 100 kb ladder, lanes 1-2: samples of 'Samchunli' (H. syriacus); lanes 3-6: four different samples of 'Simbaek' (H. syriacus); lanes 7-8: samples of 'Jinsun'; lanes 9-10: samples of 'Jamyung' (H. syriacus); lanes 11-12: samples of H. sabdariffa; lane 13: Negative control 
For unknown samples, if the primers are not universal, PCR amplification may be affected because of the presence of plant secondary metabolites. Although our method provides a novel idea for the comprehensive exploration of the genetic information among different cultivars of $H$. syriacus, to understand the ecology, distribution, and cultivar evolution of $H$. syriacus, further studies focusing on the relationship between gametophyte and genetic traits are required. Further, the method developed in this study could precisely identify heterozygotes at the locus from homozygotes for either allele without requiring restriction enzyme digestion. In addition, the results of this method are consistent with those of allele assignments derived from direct sequencing of PCR products, thereby highlighting the simplicity and reliability of our method.

In conclusion, we developed a reliable and effective method to identify the Korean and American Hibiscus cultivars, using multiplex-specific PCR. By introducing mismatches in the specific primers, dimers, hairpins, and false-positive results due to faulty primers were successfully prevented. The method does not require sequence analysis of the PCR products; instead, the products can be conveniently evaluated using conventional gel electrophoresis. Furthermore, the molecular markers developed in this study can be widely applied in the identification of medicinal plants without being influenced by the growth stage and environmental conditions.

\section{Abbreviations}

InDel: Insertion/deletion; PCR: Polymerase chain reaction; RAPD: Random amplified polymorphic DNA; RFLP: Restriction fragment length polymorphism.

\section{Supplementary Information}

The online version contains supplementary material available at https://doi. org/10.1186/s13765-021-00669-4.

Additional file 1: Fig. S1. Cytotoxic effect of Simbaek callus extract against Human Colorectal Adenocarcinoma Cell Line (HT-29 cell line).

\section{Acknowledgements}

This work was supported by Gyeonggido Business \& Science Accelerator (GBSA) Grant funded by the Gyeonggi provincial government, Republic of Korea.

\section{Authors' contributions}

RW: methodology, writing —original draft. SYP: sample preparation, SWP: funding acquisition. AMP: investigation. Y-JK: supervision, project administration. All authors read and approved the final manuscript.

\section{Funding}

No funding was received for the current study.

\section{Availability of data and materials}

Not applicable.

\section{Declarations}

Ethics approval and consent to participate

Not applicable.

Consent for publication

Not applicable.

\section{Competing interests}

The authors declare that there is no conflict of interest.

\section{Author details}

${ }^{1}$ Graduate School of Biotechnology, and College of Life Science, Kyung Hee University, Yongin, Gyeonggi-do 17104, Republic of Korea. ${ }^{2}$ SD Biotechnologies Co., Ltd, Ganseo-gu, Seoul 07793, Republic of Korea.

Received: 6 October 2021 Accepted: 23 December 2021

Published online: 31 December 2021

\section{References}

1. Hsu RJ, Hsu YC, Chen SP, Fu CL, Yu JC, Chang FW, Chen YH, Liu JM, Ho JY, Yu CP (2015) The triterpenoids of Hibiscus syriacus induce apoptosis and inhibit cell migration in breast cancer cells. BMC Complement Altern Med 15:1-9. https://doi.org/10.1186/s12906-015-0592-9

2. Molagoda IMN, Lee KT, Choi YH, Kim GY (2020) Anthocyanins from Hibiscus syriacus L. inhibit oxidative stress-mediated apoptosis by activating the Nrf2/HO-1 signaling pathway. Antioxidants 9(1):42-60. https://doi. org/10.3390/antiox9010042

3. Kim YH, Im A, Park BK, Paek SH, Choi G, Kim YR, Whang WK, Lee KH, Oh SE, Lee MY (2018) Antidepressant-like and neuroprotective effects of ethanol extract from the root bark of Hibiscus syriacus L. Biomed Res Int. https:// doi.org/10.1155/2018/7383869

4. Kwon SW, Hong SS, Kim Jl, Ahn IH (2003) Antioxidant properties of heattreated Hibiscus syriacus. Biol Bull Russ Acad Sci 30:15-16

5. Barik S, Senapati SK, Aparajita S, Mohapatra A, Rout GR (2006) Identification and genetic variation among Hibiscus species (Malvaceae) using RAPD markers. Zeitschrift für Naturforsch C 61:123-128. https://doi.org/ 10.1515/znc-2006-1-222

6. Mondini L, Noorani A, Pagnotta MA (2009) Assessing plant genetic diversity by molecular tools. Diversity 1:19-35. https://doi.org/10.3390/d1010 019

7. Newman TL, Tuzun E, Morrison VA, Hayden KE, Ventura M, McGrath SD, Rocchi M, Eichler EE (2005) A genome-wide survey of structural variation between human and chimpanzee. Genome Res 15:1344-1356. https:// doi.org/10.1101/gr.4338005

8. Mills RE, Luttig CT, Larkins CE, Beauchamp A, Tsui C, Pittard WS, Devine SE (2006) An initial map of insertion and deletion (INDEL) variation in the human genome. Genome Res 16:1182-1190. https://doi.org/10.1101/gr. 4565806

9. Lovett ST (2004) Encoded errors: mutations and rearrangements mediated by misalignment at repetitive DNA sequences. Mol Microbiol 52:1243-1253. https://doi.org/10.1111/j.1365-2958.2004.04076.x

10. Mullaney JM, Mills RE, Pittard WS, Devine SE (2010) Small insertions and deletions (INDELs) in human genomes. Hum Mol Genet 19:R131-R136. https://doi.org/10.1093/hmg/ddq400

11. Terakami S, Matsumura Y, Kurita K, Kanamori H, Katayose Y, Yamamoto T, Katayama H (2012) Complete sequence of the chloroplast genome from pear (Pyrus pyrifolia): genome structure and comparative analysis. Tree Genet genomes 8:841-854 https://doi.org/10.1186/s40064-016-3702-3

12. Wu DH, Wu HP, Wang CS, Tseng HY, Hwu KK (2013) Genome-wide InDel marker system for application in rice breeding and mapping studies. Euphytica 192:131-143

13. Păcurar DI, Păcurar ML, Street N, Bussell JD, Pop TI, Gutierrez L, Bellini C (2012) A collection of INDEL markers for map-based cloning in seven Arabidopsis accessions. J Exp Bot 63:2491-2501. https://doi.org/10.1093/ jxb/err422

14. Tian XR, Lv SX, Tian HL, Wang RB, Wang HT (2020) Development of an accurate and reliable DNA method for botanical origin authentication of 
ginseng food products. J Food Compos Anal. https://doi.org/10.1016/j. jfca.2020.103419

15. Liu B, Wang Y, Zhai W, Deng J, Wang H, Cui Y, Cheng F, Wang X, Wu J (2013) Development of InDel markers for Brassica rapa based on wholegenome re-sequencing. Theor Appl Genet 126:231-239. https://doi.org/ 10.1007/s00122-012-1976-6

16. Landegren U, Nilsson M, Kwok PY (1998) Reading bits of genetic information: methods for single-nucleotide polymorphism analysis. Genome Res 8(8):769-776. https://doi.org/10.1101/gr.8.8.769

17. Androsiuk P, Jastrzębski JP, Paukszto Ł, Makowczenko K, Okorski A, Pszczółkowska A, Chwedorzewska KJ, Górecki R, Giełwanowska I (2020) Evolutionary dynamics of the chloroplast genome sequences of six Colobanthus species. Sci Rep 10:1-14. https://doi.org/10.1038/ s41598-020-68563-5

18. Aagesen L, Medan D, Kellermann J, Hilger HH (2005) Phylogeny of the tribe Colletieae (Rhamnaceae)-a sensitivity analysis of the plastid region trn L-trn F combined with morphology. Plant Syst Evol 250:197-214

19. Lang P, Dane F, Kubisiak TL (2006) Phylogeny of Castanea (Fagaceae) based on chloroplast trn TLF sequence data. Tree Genet Genomes 2:132-139. https://doi.org/10.1007/s11295-006-0036-2

20. Silva AJ, Hellberg RS (2020) DNA-based techniques for seafood species authentication. Adv Food Nutr Res 95:207-255. https://doi.org/10.1016/ bs.afnr.2020.09.001

21. Kwon HY, Kim JH, Kim SH, Park JM, Lee H (2016) The complete chloroplast genome sequence of Hibiscus syriacus. Mitochondrial DNA A DNA Mapp Seq Anal 27(5):3668-3669. https://doi.org/10.3109/19401736.2015.10798 47

22. Gull S, Haider Z, Gu H, Raza Khan RA, Miao J, Wenchen T, Uddin S, Ahmad I, Liang G (2019) InDel marker based estimation of multi-gene allele contribution and genetic variations for grain size and weight in rice (Oryza sativa L.). Int J Mol Sci 20(19):4824. https://doi.org/10.3390/ijms20194824

23. Valentini A, Pompanon F, Taberlet P (2009) DNA barcoding for ecologists. Trends Ecol Evol 24:110-117. https://doi.org/10.1016/.jtree.2008.09.011

24. Chariton A (2012) Short and informative DNA products to indirectly measure vascular plant biodiversity. Mol Ecol 21(15):3637-3639. https:// doi.org/10.1111/j.1365-294X.2012.05633.x

\section{Publisher's Note}

Springer Nature remains neutral with regard to jurisdictional claims in published maps and institutional affiliations.

\section{Submit your manuscript to a SpringerOpen ${ }^{\odot}$ journal and benefit from:}

- Convenient online submission

- Rigorous peer review

- Open access: articles freely available online

- High visibility within the field

- Retaining the copyright to your article 